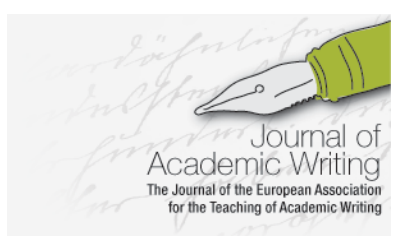

Journal of Academic Writing

Vol. 10 No 1 WINTER 2020, pages 213-220 https://doi.org/10.18552/joaw.v10i1.582

\title{
Analyzing Writing Style and Adapting to a New Writing Culture: A Teaching Practice
}

\author{
Charity Givens \\ LCC International University, Lithuania
}

\begin{abstract}
This teaching practice presents a classroom exercise completed in a first-year composition class at an English-medium private university in Lithuania. The course typically takes place in the second semester of the year and is required for all first-year students, who are multilingual but completing their university degree in English. The instructor, a US speaker of English who has a background in US composition studies, leads the exercise that consists of a writing style analysis that examines sentence length, word variety, and sentence emphasis, concluding with a discussion of how students can adapt their writing style to meet the needs of a new audience. The exercise aims to help students understand their writing style and what they need to know to adapt their style to fit the academic writing context in the university.
\end{abstract}

\section{Introduction}

Zamel (1997) wrote of the problems of framing the writing classroom in terms of dominant writing cultures, and argued:

[E]ducators ... need to bring the same kind of skepticism to bear on [their] tendency to believe that the norms that seem to exist in one language or culture predetermine or are in opposition to what an individual is likely to be able to do or accomplish in another. (p. 34)

The writing classroom, then, should be a place for students to discover that their writing serves a rhetorical purpose beyond fitting into a specific mold for solely one style. According to Horner et al. (2011), the differences in language use are not "a barrier to overcome or ... a problem to manage, but ... a resource for producing meaning in writing, speaking, reading, and listening" (p. 303). Students should be given the opportunity to make choices about elements of style in their writing in order to reach their intended audience. Without a specific way to analyze and the occasion to reflect, though, the writing classroom - even with all of its good intentions - can remain a retraining writing boot camp that seeks to dismantle and rebuild in the image of the dominant writing style.

At the university where I teach, an international English-medium university whose students represent more than 70 countries, the students are required to pass a first-year composition class in two consecutive semesters. Written Composition, taken in the first semester, devotes itself to critical thinking and writing competencies. The 2019-2020 Academic Catalog (LCC International University, 2019) specifies that "students will develop the skills necessary for understanding and writing texts in an academic setting" (p. 98). In the second semester, students take Academic Writing, which "focuses on introductory research writing processes" ( $p$. 98). The course syllabus for ENG 114 Academic Writing (LCC International University English Department, 2020) contains several course learning outcomes derived from program outcomes, one of which is that students will: 
Create a variety of expository texts which exhibit critical thinking, an awareness of audience, and strong writer's voice with an understanding of the social effects of language as well as a commitment to open dialogue. (p. 1)

In order to meet this learning outcome, near the end of the Academic Writing class, right before the students begin writing their research paper - the capstone project for the class - I guide students through an exercise that helps them analyze their writing style. The students use a paper that they have written in a different class; most often, they use papers from a core class in their first year, like a history class or a literature class since those often require writing as a form of assessment.

We then discuss the rhetorical effects their writing style may elicit from their audience. Since the class teaches students how to "[c]onstruct well-organized, rhetorical arguments in academic essays" (LCC International University English Department, 2020, p. 1), we discuss what students can do to adapt their writing to fit the needs of the intended audience of an academic essay, including not only the artificial audience of the teacher grading the work but also the broader academic audience comprising other professors who they might write for as well as students studying and writing about similar topics. The two-part process fills three classroom contact hours in one week, which are devoted to the initial exercise of style analysis, and then at least two other contact hours in a separate week, which are devoted to discussing the results. The students also write a reflection that summarizes their results and comments on how they might adapt their writing both in the upcoming research paper and eventually as academic writers in the university.

The style analysis, then, prepares students to use their style in different ways to reach different audiences. I liken writing to advanced mathematics: one needs to know basic arithmetic in order to do mathematics, but solving $1+1=2$ is quite different from solving Fermat's Theorem. So, too, with writing: one needs to know basic grammar rules, but writing grammatically correct sentences is different from writing effectively to reach an audience. Therefore, they can adapt their writing, discovering how to bring the useful features of their home language to the world of academic English. Our classroom discussion of adaptation becomes the most powerful part of the whole exercise because it places choices in the hands of students. The classroom discussions happen in several stages throughout the process, beginning with shorter, capsule whole-class discussions about each element of analysis as we complete them and ending with two class periods devoted to discussing the effects of their writing style choices.

This paper discusses a classroom exercise used to help students examine their writing and proposes specific metrics for analysis so that students may make informed choices about modifying their writing style.

\section{Analyzing Writing Style}

Style has been defined traditionally as how writers express their ideas in written words (Abrams, 1993; Pinker, 2015; Brown, 2018). In addition to content knowledge and knowledge about conventions of specific discourse, successful writing style depends on several characteristics, some of which may relate to length, text cohesion, and complex sentence structures (Crossley et al., 2014). Academic writing style, specifically, requires more elaborate vocabulary and sentence structures than more casual forms of writing (Staples et al., 2016). Additionally, academic writing in English often prizes clarity and conciseness as markers of good writing (Strunk, 2018; Graves, 7 October 2019). Thus, first-year students unaccustomed to a new style of writing in a second language may find themselves floundering when thinking about how to write a successful paper in university, given not only the content but also the style present in writing in academic English.

Before students can adapt their writing style, they must be able to identify elements of their academic writing style. With quantitative measurements that give numbers to analyze, students begin to see patterns that they might not have noticed before - using many extra-long sentences, for instance, or relying on limited word choices, or writing only compound sentences. 
Since the conventions of academic writing limit personal choice, students need to be able to identify their writing style so that they can adapt to these conventions.

The writing style analysis originated from an MIT Comparative Media Studies Writing (n.d.) exercise and has been adapted over several years to address student concerns about their writing. It consists of several parts: analyzing sentence length, unique words, and sentence emphasis. Though programs exist that can calculate these elements automatically (e.g., Expresso App and Analyze My Writing), students find that slowing their pace and concentrating on individual parts creates awareness of their writing. For this reason, I also require the analysis be hand-written, causing them to pay attention to what they analyze. With each part, students also reflect on their writing, explaining the effects it may have on their audience. This reflection happens both through classroom discussions about their results and a written reflection asking them to describe their results and what effect they think they may have had on the instructor feedback.

\section{Sentence length}

The first part of the exercise requires students to count the words in each sentence and record the numbers in order on another piece of paper. Additionally, they label their sentences as long, medium, and short. The MIT exercise defines long sentences as 46-70 words, medium as 2145 words, and short as 1-20 words, which provides a common definition for labeling the sentences.

After students have counted and labeled their sentences, we discuss the possible rhetorical effects of sentence length on their audience. Drawing students' attention to the effect empowers them to use it consciously. Because of the conventions of academic English, short sentences are often perceived to indicate simpler thought or heightened emotion, but used strategically, they can draw attention to an important concept. Longer sentences can allow for more development in one sentence, but too many long sentences have a soporific effect on the reader (Clark, 2016).

Students reflect on the effect of their sentence patterns, an essential part of the exercise. Without reflection, these kinds of exercises turn into pointless busy work (Moe, 2018, p. 72); thus, reflection must accompany analysis so that students can think on paper about the effect of their sentences. One of the reflection questions concerns how students perceive a paper with many short sentences, and we discuss how short sentences can affect perceptions of fluency or knowledge. We discuss differences in books written for children versus textbooks for a university audience. I share with them my experiences learning Lithuanian, relying often on the shortest possible sentences in search of clear communication in a new language context. We talk about the rhetorical effect this has on my audience, some speaking more slowly to me or some switching to English. As a learner of the Lithuanian language, I share with them my worries about appearing too simple in speaking with others. We then focus on how this situation might apply to writing. Students have revealed that they feel like 'bad' writers if they use simple sentences. We discuss how that concern affects their self-perception as writers. This dialogue requires trust and encouragement, and addressing their self-perceptions gives them a safe space for redefining effective writing.

As the students discuss these ideas and how they might perceive of themselves as writers, I ask them to consider places where short sentences are not just effective, but necessary. This discussion gives room to consider both how others might perceive shorter sentences and how the students can use them with a clear rhetorical purpose. Often, they conclude that important points belong in shorter sentences because this allows for direct communication.

Previous research done at the university about L1 rhetorical styles has uncovered student perceptions about rhetorical structures in their home language: students whose L1 is Georgian, for instance, report that they prefer "sophisticated vocabulary and lang[uage] structure"; students whose L1 is Russian report that they use rich vocabulary and references to great literature (Yoder, 2015). These statements reflect students' awareness of rhetorical conventions in their home language, which helps them frame the way they understand rhetorical conventions in written English and gives reasons why they make certain rhetorical 
choices in written English. Some of my students have commented that longer sentences seem pretentious because of their previous instruction in writing in their first language. Furthermore, even though they may have been taught to use long sentences in their home language, writing long sentences in English feels foreign. When students examine their understanding of conventions of writing in their home language, they can make different choices about how they want to adapt their writing to fit academic writing in English.

\section{Unique words}

In the next step, students mark any unique words in their document. Sometimes this means long, multi-syllabic words, and sometimes it means any words that they would not regularly use in conversation or casual writing. Admittedly, this can be a subjective measurement, but it calls to attention the lexical sophistication of their writing (Crossley et al., 2014, p. 186). An app that I use to help analyze writing, Expresso App, defines rare words as '[w]ords outside of the 5000 most frequently used English words' and uses the Corpus of Contemporary American English to find those words (Panko, n.d.). The purpose of this app is not to provide an exhaustive list of words that could be used in writing, but rather to give the students a user-friendly application to give a general measure of their word choice variety. They also use this feature to look for the words that they have used the most (excluding grammatically necessary words like articles).

\section{Labeling academic writing style}

After students have examined their sentences and words, they can label their academic writing style. Graves (17 October 2019) provides a helpful framework for describing academic style: low or plain, middle or forcible, and high or elaborated. In a podcast on styles of academic writing, he shows how different academic writing styles have different effects on audiences (Graves, 7 October 2019). In a separate podcast on the low or plain style of writing, he argues that for academic writing favoring clarity and conciseness, the low or plain style creates useful writing that audiences understand more easily (Graves, 17 October 2019). Oftentimes, my students balk at the idea of writing in this unvarnished way, but as we compare the effects of plain writing versus florid writing on different audiences, they begin to consider how their writing may reflect how they are thinking.

In a textbook on style and clarity, Williams (2006, p. 11) argues that "when we want to hide the fact that we don't know what we're talking about, we typically throw up a tangle of abstract words in long, complex sentences." He further suggests other influences on unclear writing, such as imitating what students think experts want or writing in an unfamiliar area. In my classroom, some students have disclosed that they prefer writing in the florid style because they can hide weaker ideas behind complicated words and complex sentences. They are aware that conventions of academic writing make it more complex than other writing, but because they do not necessarily have developed ideas this early in their academic career, they sometimes prefer to make up for this deficit by using the florid style to pad their work. For some students, then, the florid style may indicate that they fit into their new academic context or prove to themselves that they deserve to be there.

The plain style, where writers communicate their ideas precisely and concisely, can be terrifying, and I challenge students to focus on developing strong ideas as they refine their written communication. Since we are completing this exercise shortly before they begin writing their research paper, they need to feel confident that their knowledge and research is strong enough to be expressed in the plain style.

\section{Sentence type and emphasis}

After students have examined sentence length and labeled the academic style (low, middle, or high) in their paper based on sentence length and word variety, they finally examine sentence emphasis. When discussing syntax with my students, we analyze the most common sentence order in the English language - subject/verb/object - and discuss ways to change the order to create a new effect. Students have two jobs in this part of the exercise: they must label what type of sentence they have (simple, compound, complex, or compound-complex) and where the important information occurs in the sentence. More than just rote labeling of grammar, this 
is a rhetorical approach to grammar that teaches thinking and helps students convey the relationships between themselves and the world (Kolln, 1996; Micciche, 2004).

After defining and labeling the types of sentences, we discuss how the sentence type affects the relationship of ideas in the sentence so that students can pick the best sentence type to convey their information. Sentence clauses demonstrate relationships between ideas and develop coherency in a text (Matthiessen 2002; Green, 2014; Grano \& Ohio Library and Information Network, 2016; Basterrechea \& Weinert, 2017), and combining different kinds of clauses creates the different types of sentences introduced above. I focus on broad clause types here: dependent and independent only. I frame this part of the discussion in terms of the power relationship of ideas. Simple sentences indicate that a single idea is important enough to be understood on its own. Compound sentences indicate that two or more ideas exist and that they are of equal importance. We see this demonstrated by the function of coordinating conjunctions (Verstraete, 2005). Complex sentences indicate that two or more ideas exist, but that they are unequal: one idea has more power than the other. We see this demonstrated by subordinating conjunctions (Lakoff, 1984). The compound-complex sentence develops ideas with equal power but also demonstrates that the main ideas are often influenced by additional information that may not be as important. When analyzing the argumentative thesis statement, for example, students can leverage the power of the complex sentence to demonstrate their position on the topic (in the independent clause) as well as the other side's position (in the dependent clause).

Once students understand how sentence type conveys these relationships, we discuss how sentence emphasis conveys meaning. For this aspect, we review how people process information: known information should come before new information as a bridge to cohesive ideas (Lingard, 2019; Strunk, 2018). Pinker (2015) highlights the difficulties with keeping sentence information in ineffective or confusing places in his discussion of the web, the tree, and the string, explaining that too much emphasis in left branching sentences requires too much memory load on the reader due in part to the way that the English language is processed. Students look for places where their writing would benefit from rearrangement so that strong ideas are emphasized instead of lost in syntax.

I also describe and demonstrate the effects of different sentence type choices. One exercise, adapted from 'Sequence for Teaching the Sentence' (Moe, 2018) is particularly helpful here: students take one sentence from the writing they have analyzed and rewrite it five different ways, paying attention to sentence type and word order. They may take a complex sentence and transform it to a compound one to see the effect on the relationship of the information. They may reverse the order so that the end of the old sentence is the beginning of the rewritten sentence to see how the changed emphasis affects the information. Students then have a personal example of the different choices that they can make, and they see how small changes can create different effects on the audience.

As we analyze style, I emphasize that we are not looking for right or wrong writing; rather, we are looking for the patterns that develop in their writing so that they can make informed choices about what they would like to change in their writing or even what they would like to keep or strengthen. Thus, the purpose here is not simply error correction or merely grammar labeling but rather writing awareness with an eye to the rhetorical effects of their sentences on the audience. Pinker's (2015) ideas on learning style are helpful here, arguing that learning writing should not be a boot camp of avoiding obstacles, but challenging learning writers to "think of it [writing] instead as a form of pleasurable mastery, like cooking or photography ... Perfecting the craft is a lifelong calling, and mistakes are part of the game" (p. 82). Understanding their patterns helps students perfect their writing craft as they consider the effect on their audience. I also follow up this discussion when we polish the research paper in the revision stage. 


\section{Conclusion}

This particular writing practice provides a framework for analysis and an opportunity for discussion and reflection, opening up the writing classroom and creating an environment that produces informed students who are not simply told to make changes so their writing is better, but encouraged to experiment with writing so that they have a chance to own their writing style and use it as they see fit to reach their intended audience.

Entering an English-medium university and learning a new way of writing creates different opportunities for my students. With this experience comes reflection and revision of their current writing and the context in which they previously wrote. Sometimes, students believe that they have been taught incorrectly or have missed out on some important aspect of writing. Their position is often unfortunately reinforced in their new writing context, an English-medium university staffed by a majority of native English speakers, many of whom were educated in North America. Some students remark that they consciously self-edit their voice for fear of sounding wrong or incorrect. They may not want to bring their home language voice into English because it differs from academic writing in English.

I address these fears by reminding students of two things: first, that English is a living language that changes and adapts through use, and second, that there are more non-native English writers in the world now than native English writers. Thus, they are not alone in their writing, but rather, part of a larger community that actively participates in adapting the English language.

Moreover, as the instructor, I must remember the challenges that my own orientation brings. I have learned several ways of writing, but I have been oriented to North American styles of writing that favor brevity and clarity. As the students are encouraged to branch out and learn a different way to write, I also need to acknowledge that the style I teach is not always the best option, nor is it the only way to write. When students are empowered to analyze their writing, to see their writing patterns, and to understand the rhetorical effects on specific audiences, they are able to make informed choices about how to write. Admittedly, it is a delicate operation, and my skeptic's lens often needs to be refocused. However, if students know why writing choices matter, they can adapt to almost any writing context. 


\section{References}

Abrams, M. H. (1993). A glossary of literary terms. (7th ed.) Thomson Learning.

Brown, S. C. (2018). Nurturing students' natural writing style to better communicate research to the public. Scholarship of Teaching and Learning in Psychology, 4(1), 43-54. https://doi.org/10.1037/stl0000103

Basterrechea, M. \& Weinert, R. (2017). Examining the concept of subordination in spoken L1 and L2 English: The case of if-clauses. Tesol Quarterly, (51)4, 897-919. https://doi.org/10.1002/tesq.361

Crossley, S., Rosoe, R., and McNamara, D. (2014) What is successful writing? An investigation into the multiple ways writers can write successful essays. Written Communication, 31(2), 184-214. https://doi.org/10.1177/0741088314526354

Clark, R. P. (2016). Writing tools: 55 Essential strategies for every writer. (10 ${ }^{\text {th }}$ anniversary ed.) Little, Brown Spark.

Graves, R. (Host). (7 October 2019) Styles of academic writing [audio podcast episode]. In Teaching writing: Ideas and strategies. Podomatic.

https://www.podomatic.com/podcasts/rogergraves/episodes/2019-10-07T11 44 32$\underline{07 \quad 00}$

Graves, R. (Host). (17 October 2019). The plain or low style [audio podcast episode]. In Teaching writing: Ideas and strategies. Podomatic.

https://www.podomatic.com/podcasts/rogergraves/episodes/2019-10-17T10 54 19$\underline{07 \quad 00}$

Green, C. (2014). An analysis of the relationship between cohesion and clause combination in English discourse employing NLP and data mining approaches. Digital Scholarship in the Humanities, 30(3), 326-343. https://doi.org/10.1093/llc/fqu012

Grano, T., \& Ohio Library and Information Network. (2015). Control and restructuring (1st ed.). Oxford: Oxford University Press. https://doi.org/10.1093/acprof:0so/9780198703921.001.0001

Horner, B., Lu, M.-Z., Royster, J.J., \& Trimbur, J. (2011). OPINION: Language difference in writing: Toward a translingual approach. College Writing, 75(3), 303-321.

Kolln, M. (1996). Rhetorical grammar: A modification lesson. The English Journal, 85(7), 2531. https://doi.org/10.2307/820503

Lakoff, G. (1984). Performative subordinate clauses. Berkeley Linguistics Society, 10, 472 480. https://doi.org/10.3765/bls.v10i0.1953

LCC International University. (2019). 2019-2020 Academic catalog: Undergraduate programs. https://lcc.lt/assets/ba-catalog-2019-2020-min.pdf

LCC International University English Department. (2020). ENG 114: Academic writing course syllabus. Klaipeda.

Lingard, L. (2019). Pace, pause \& silence: Creating emphasis \& suspense in your writing. Perspectives on Medical Education, 9, 57-59. https://doi.org/10.1007/s40037-019$\underline{00556-1}$

Matthiessen, C. (2002). Combining clauses into clause complexes: A multi-faceted view. In Bybee, J. and Noonan, M. (Eds.), Complex sentences in grammar and discourse: Essays in honor of Sandra A.Thompson. Benjamins, pp. 235-319. 
Micciche, L. (2004). Making a Case for Rhetorical Grammar. College Composition and Communication, 55(4), 716-737. https://doi.org/10.2307/4140668

MIT Comparative Media Studies. (n.d.). Analyzing your own style. https://cmsw.mit.edu/writingand-communication-center/analyzing-style/

Moe, P. (2018). A sequence for teaching the sentence. Teaching English in the Two-Year College, 46(1), 70-83.

Panko, M. (n.d) Metrics for editing. Expresso App. https://www.expresso-app.org/metrics

Pinker, S. (2015). The sense of style: The thinking person's guide to writing in the $21^{\text {st }}$ century. [Kindle ed.]. Penguin Books.

Staples, S., Egbert, J., Biber, D., \& Gray, B. (2016). Academic writing development at the university level: Phrasal and clausal complexity across level of study, discipline, and genre. Written Communication, 33(2), 149-183.

https://doi.org/10.1177/0741088316631527

Strunk, W. (2018). The elements of style: Classic edition 2018 update. [Kindle ed.] (R. De A'Morelli, Ed.) Spectrum Ink Publishing.

Verstraete, J.-C. (2005). Two types of coordination in clause combining. Lingua, 115(4), 611626. https://doi.org/10.1016/..lingua.2003.09.018

Williams, J. (2006). Style: Lessons in clarity and grace. (9th ed.) Pearson.

Yoder, M. (2015, June 16). Utilizing Knowledge of Students' Previous L1 and English Written Rhetoric Instruction to Inform Instruction of Written Rhetorical Styles in English [conference presentation]. $8^{\text {th }}$ Conference of the European Association for the Teaching of Academic Writing (EATAW), Tallinn.

Zamel, V. (1997). Towards a model of transculturation. TESOL Quarterly, 31(2), 341-352. https://doi.org/10.2307/3588050 